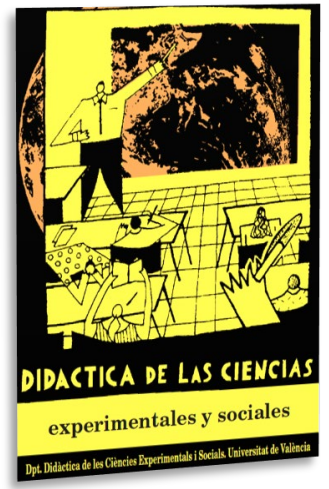

\title{
Didáctica de las violencias del siglo XX: Enzo Traverso y el concepto de Guerra civil europea
}

\author{
Didactics of the 20th century violence: Enzo \\ Traverso and the concept of European Civil \\ War
}

DOI:10.7203/DCES.39.15665

\author{
Gustavo Hernández Sánchez \\ Fedicaria-Salamanca, gustavohernandezhistoria@gmail.com \\ ORCID iD: https://orcid.org/0000-0002-3104-1476
}

\begin{abstract}
RESUMEN: El siguiente artículo presenta una propuesta didáctica para explicar las violencias del siglo XX a través del concepto de Guerra Civil Europea empleado por el historiador italiano Enzo Traverso. Este autor lo entiende como un ciclo histórico que transcurre entre el inicio de la Gran Guerra y el fin de la Segunda Guerra Mundial, y rechaza la idea ampliamente aceptada de un enfrentamiento entre liberalismo y totalitarismos, presentando una visión más compleja. A través de la reflexión sobre su obra, se valora su aplicación en relación con la 〈didáctica crítica de las ciencias sociales〉. De este modo, se presentan la Historia, así como su docencia y sus usos públicos, como un campo de estudio continuamente revisitado desde el presente y repleto de debates historiográficos que pueden ser utilizados en el aula, dotando a la materia de utilidad en la configuración de ciudadanías tolerantes.
\end{abstract}

Palabras Clave: Guerra Civil Europea, violencias del siglo XX, didáctica crítica de las Ciencias Sociales, usos públicos de la historia.

ABSTRACT: The following work presents a didactic proposal to explain the violence of the 20th century through the concept of the European Civil War used by the Italian historian Enzo Traverso. This author understands it as a historical cycle that takes place between the beginning of the Great War and the end of the Second World War and rejects the widely accepted idea of a confrontation between liberalism and totalitarianism, presenting a more complex vision. Through the reflection on his work, its application in relation to the «critical didactics of the Social Sciences is valued. In this way, History is presented, as well as its teaching and public use, as a field of study continuously revisited from the present and full of historiographical debates that can be used in the classroom, providing the subject with usefulness in the configuration of tolerant citizenships.

KEYWORDS: European Civil War, 20th century violence, critical didactics of the Social Sciences, public use of History.

Fecha de recepción: julio de 2019

Fecha de aceptación: enero de 2020

Este artículo se enmarca dentro del Proyecto de Innovación Docente "Diseño de un modelo didáctico para la enseñanza y aprendizaje de los conceptos políticos y sociales", referencia 69/2019 de la Universidad Complutense de Madrid. El autor es, además, miembro de Fedicaria-Salamanca. 


\section{INTRODUCCIÓN: UN PASADO EN DIALÉCTICA CON EL PRESENTE}

Como docente del campo de estudio de la Historia, a menudo uno se sorprende de las simplificaciones que se ve forzado a realizar, ya sea por el contexto educativo, ya sea por las dinámicas cotidianas implícitas en los procesos de enseñanza-aprendizaje, esto es, el tiempo en el aula. Enseñar y aprender cuestiones complejas a menudo requiere de un esfuerzo que no siempre nosotros ni nuestros alumnos y alumnas estamos dispuestos a realizar. Ese proceso alquímico, siguiendo la metáfora empleada por Julio Mateos, en el que el docente debe saber transformar el conocimiento científico en otro de naturaleza divulgativa sin desdibujar su esencia, probablemente sea, en efecto, tan sólo una quimera. No obstante, en algunos felices momentos, nos cruzamos no con magos o alquimistas, pero sí con propuestas interpretativas capaces de abordar problemas complejos de manera brillante, los cuales nos ofrecen claves para explicar y reflexionar la historia desde una perspectiva crítica, alejada de simplificaciones que pudieran traer consigo un sesgo ideológico en beneficio del statu quo imperante en las sociedades del capitalismo tardío. Dentro de los relatos históricos convencionales o hegemónicos, la idea de progreso y el modo de producción capitalista comparecen a menudo como el fin teleológico de la historia, comprehendida como disciplina al servicio del relato construido desde el poder y de marcado carácter positivista. Tal y como desvela Raimundo Cuesta en La venganza de la Memoria y las paradojas de la Historia, la Historia se ha erigido a menudo como una memoria del poder, especialmente a raíz de la formación del Estado Moderno, pero también en relación a periodos que preceden y suceden a esta forma de domino. De este modo, la Historia:

Se constituye en parte insustituible del aparato del Estado y de la producción de los imaginarios nacionales. La historia se pone al servicio de la construcción de una memoria social cada vez más invasiva de la esfera pública (...) Se afianza, de esta suerte, una nueva experiencia del tiempo histórico, como destino manifiesto, y unas nuevas relaciones entre el presente, el pasado y el futuro, un nuevo régimen de historicidad (Cuesta, 2015, p. 52).

Cuestión que quizá no haya cambiado tanto, salvando las distancias, desde el siglo XIX. Mirar las ciencias sociales, en este caso la historia, a través de esta óptica es, desde nuestro punto de vista, vaciarlas de contenido crítico, de utilidad práctica en un contexto en que su menosprecio por parte del régimen de historicidad (y de verdad) de las sociedades del capitalismo tardío a menudo viene definido precisamente por esta situación paradójica, al no encontrar en ellas un carácter útilcompetencial, si tuviésemos que emplear cierto neolenguaje pedagógico. Se hace necesario, por tanto, aportar otros puntos de vista, quizá no tan difíciles de aplicar en el aula. Visiones periféricas en las que estas se conviertan en una herramienta de reflexión y extrañamiento respecto de las ideas hegemónicas que a menudo nos son dadas. Esta operación exige repensar el pasado en "confrontación dialéctica con el presente" (Cuesta, 2015, p.70), como una manera, al mismo tiempo, si esto fuese necesario, de cargar de utilidad los contenidos que tratamos de transmitir a nuestros alumnos y a nuestras alumnas, con el objetivo de conformar ciudadanías críticas. En este caso, las diferentes cuestiones abordadas en este artículo, se centran preferentemente en los contenidos del currículo contenido en los cursos de 4 de ESO y $1^{\circ}$ de Bachillerato para la materia de Historia, relativos a Historia del mundo contemporáneo, en los que se basa nuestra propuesta didáctica. Concretamente, reflexionaremos en torno al trabajo de campo desarrollado durante el curso 2018-2019 con varios cursos de $1^{\circ}$ de Bachillerato en la Escuela de Arte de Salamanca.

Considero que, recientemente, una de las aportaciones más importantes en esta línea es la que hace el historiador italiano Enzo Traverso ${ }^{1}$, la cual guarda un componente hermenéutico común con

\footnotetext{
${ }^{1}$ Enzo Traverso es un historiador italiano. Actualmente es catedrático en la Universidad de Cornell (Ithaca, Nueva York). Estudió en la Universidad de Génova y fue profesor en la Universidad de Picardía y la Escuela de Altos Estudios en Ciencias Sociales (EHESS) de París. Entre sus temas de investigación destacan su crítica a la idea tradicional de
} 
lo que desde Fedicaria ${ }^{2}$ se entiende como una "didáctica crítica de las ciencias sociales". Por tanto, la orientación pedagógica y propuesta teórico-práctica en la que se inserta esta contribución es la de la denominada "didáctica crítica de las ciencias sociales", la cual entiende la pedagogía como "un tipo de relación social inscrita en las relaciones de poder operantes en la escuela" y tiene por objeto "la reorientación de tales prácticas", fundándose en torno a tres vectores, a saber: "la crítica de la cultura, el análisis genealógico y una forma alternativa de política de la cultura" (Cuesta, Mainer, Mateos, Merchán y Vicente, 2005, p. 20). Cultura, historia y política forman parte y dibujan el trípode sobre el que se levanta y construyen los postulados del discurso crítico. En este artículo, siguiendo estos planteamientos, abordaremos las aristas didácticas de la obra de Traverso en torno al concepto de Guerra Civil Europea para interpretar las violencias del siglo XX. Nos referimos al espacio cronológico comprendido entre el inicio de la Primera Guerra Mundial (1914) y el final de la Segunda Guerra Mundial (1945), en el que comparecen, entre otros acontecimientos, la barbarie del Holocausto como uno de los sucesos centrales del siglo XX en Europa, en torno al cual reflexionaron también los autores de la denominada Escuela de Frankfurt, y cuyas reflexiones (o sombras) se proyectan hacia las sociedades actuales, con un auge preocupante en el presente de lo que este autor define como posfascismo ${ }^{3}$.

Por tanto, los contenidos para esta propuesta didáctica, de acuerdo con lo recogido en el Real Decreto 1105/2014, de 26 de diciembre, por el que se establece el currículo básico de la ESO y del Bachillerato, son preferentemente los recogidos en el bloque 5. La época de "Entreguerras" (19191945) para la ESO (Sec. I. p. 302), y el bloque 5. El periodo de "Entreguerras", la Segunda Guerra Mundial y sus consecuencias para Bachillerato (Sec. I. p. 344), tal y como desarrollaremos de manera más detallada a lo largo de estas páginas ${ }^{4}$.

No por casualidad Traverso es uno de los mejores especialistas en la cultura de este periodo. En su bagaje comparecen lecturas comunes que nos parecen fundamentales, entre las que destaca la obra de Walter Benjamin, la cual es de gran utilidad para comprender las sociedades del presente, o el propio campo de estudio de la historia, tal y como dejó recogido en su último manuscrito, Tesis sobre filosofía de la historia (1940), antes de suicidarse en Portbou perseguido por la policía nazi, ese mismo año ${ }^{5}$. Tal y como entienden también este campo de estudio muchos de los autores que iremos citando a lo largo de estas páginas. Nos servirán, de este modo, las cuestiones abordadas por Traverso en torno al contexto cultural de estos años, para hacer una propuesta sobre las posibilidades de explicación de un periodo que, más allá de los contenidos relacionados con dichos acontecimientos, nos ayuden a comprender procesos históricos más amplios, como el de la propia modernidad, la idea de progreso o los distintos debates historiográficos construidos en torno a ellos. Una forma diferente de abordar nuestra materia desde la perspectiva de esta "didáctica crítica de las ciencias sociales".

totalitarismo y algunas posturas muy polémicas en torno a la configuración de la memoria del Holocausto, así como la historia intelectual que transita este periodo. Participó en los movimientos autonomistas marxistas italianos y fue militante en este país de la organización Potere Operario (Poder Obrero) en la década de los ochenta del siglo XX.

${ }^{2}$ La idea primigenia de formar lo que luego sería Fedicaria arranca de unos "seminarios de desarrollo curricular", celebrados entre 1991 y 1995. La Federación Icaria (Fedicaria) fue fundada en 1995, y desde 1997 mantiene la revista Con-Ciencia Social, cuyo abanico temático empezó siendo el fundamento teórico de la producción de una generación alternativa de materiales de enseñanza de las ciencias sociales en la educación secundaria y acabó mutando en una publicación que se extiende por un variado elenco de asuntos: desde la didáctica crítica hasta la crítica de la cultura y la educación en el capitalismo tardío. Para un análisis más detallado de esta intrahistoria véase Cuesta, 2014.

${ }^{3}$ De acuerdo con la definición de posfascismo que ofrece este autor, este se caracterizaría como un "fenómeno transitorio, en transformación, que todavía no ha cristalizado" y, por tanto, habría que diferenciarlo de la idea de neofascismo (Traverso, 2018, pp. 18-19).

${ }^{4}$ Incluyéndose también, en ambos casos, los relativos a la Primera Guerra Mundial del bloque 4 del citado decreto curricular, así como del bloque 6 de los contenidos para la ESO. Véase epígrafe 3.1.

${ }^{5}$ Para más información sobre el contexto de la época y las vicisitudes de la Escuela de Frankfurt en una época tan difícil (véase Hernández Sánchez, 2020). 


\section{ENZO Traverso: LA Historia COMO CAMPO DE BATALla}

Para ello se hace preciso, en primer lugar, desvelar la concepción de la idea de historia presente en la obra de Enzo Traverso o, al menos, algunas de sus claves, para poder ponerlas en relación posteriormente con los contenidos recogidos en el currículo para la ESO y Bachillerato. Este autor señala la pertinencia de una mirada retrospectiva, desde el presente, de los acontecimientos que marcaron la historia del siglo XX; un siglo, siguiendo la interpretación de Walter Benjamin, caracterizado por el signo de la catástrofe. De lo contrario, apunta: "se corre el riesgo de empobrecer la hermenéutica histórica" (Traverso, 2017, p. 23). Y para ello dibuja un método, el cual configura unas normas de producción del conocimiento histórico como "parámetros útiles en el ejercicio de una profesión" (Ibídem p. 26) y sin pretensión de que estos se conviertan en leyes insalvables en el ejercicio de dicha profesión, por supuesto. La primera regla sería la contextualización, necesaria para la explicación de un acontecimiento o idea en el momento de su génesis. La segunda la de un historicismo crítico el cual, a diferencia del historicismo positivista (muy en boga en la actualidad bajo formas de neohistoricismo o neopositivismo), huya de una concepción lineal de la historia. La tercera regla consistiría en comparar los acontecimientos como "una operación indispensable para tratar de comprenderlos" (Ibídem p. 26). Se trata esta de una propuesta que va más allá de los parámetros de la historia comparada y en la que también cabe una concepción diacrónica de los acontecimientos históricos. Nos parece interesante, añadir en este punto, lo que desde Fedicaria se ha entendido como una historia genealógica, es decir, aquella: "capaz de comprender lo que nos pasa hoy a través de un conocimiento histórico de los problemas que nos afectan" (Cuesta y Hernández, 2018, p. 699). Finalmente, la cuarta regla consistiría en la conceptualización, la cual hace a la propuesta de Traverso partícipe de la concepción de autores como Reinhart Koselleck en torno a la semántica de los tiempos históricos ${ }^{6}$ :

Para aprehender lo real, hay que capturarlo por medio de conceptos -"tipos ideales", si se quieresin por ello dejar de escribir la historia en un modo narrativo; dicho de otra manera, sin olvidar jamás que la historia real no coincide con sus representaciones abstractas (Traverso, 2017, p. 26).

En última instancia, como colofón a esta forma de entender la historia, dos conclusiones similares a las planteadas desde el proyecto de Fedicaria en los últimos años. En primer lugar, la idea de que escribir (y explicar) la historia sigue profundamente anclada en el presente (problematizar el presente), y es desde este desde el que siempre volvemos nuestra mirada hacia atrás, como el ángel de la novena tesis de la filosofía de la historia de Benjamin ${ }^{7}$ : "siempre es desde el presente que uno se esmera en reconstruir, pensar e interpretar el pasado" (Ibídem, p. 26). De este modo, la historia siempre participa y se ve condicionada por lo que Jürgen Habermas denominó usos públicos del pasado. Y, en segundo lugar, de nuevo en clave benjaminiana, la necesidad de reconstruir (y transmitir el pasado) desde el punto de vista de los vencidos. Idea presente también en la obra de Raimundo Cuesta que citábamos al inicio de este artículo: rescatar el pasado ausente, el pasado ignorado de los vencidos, "de modo que el tiempo pretérito deja de ser un depósito inerte de experiencias y hechos y se convierte en un objeto de confrontación dialéctica con el presente" (Cuesta, 2015, p. 70). Idea que guarda enormes similitudes con alguna de las conclusiones del propio Traverso: "surge una visión de la historia como un proceso abierto en el que un pasado inacabable puede, en ciertos momentos, ser reactivado, hacer estallar el continuum de una historia puramente cronológica y, por su irrupción repentina, inmiscuirse en el presente" (Traverso, 2017, p. 28). Sin embargo, a

\footnotetext{
${ }^{6}$ Me parecen interesantíasimas, al respecto, las aportaciones de Aurora Rivière (2020) en torno al empleo de la Historia de los conceptos para el desarrollo de ciudadanías críticas en el aula; autora a quien sin duda debo un acercamiento a la obra de Koselleck del que espero poder continuar aprendiendo como miembro del Proyecto de investigación citado en la cabecera del artículo.

${ }^{7}$ En ella Benjamin emplea la figura de un cuadro de Klee, Angelus Novus, cuyo aspecto, en palabras de este autor, posee el aspecto del ángel de la historia.
} 
pesar de estas notas, todavía no hemos delimitado cómo desde estos presupuestos teóricometodológicos, podemos reflexionar, interpretar y explicar con nuestros alumnos y alumnas las violencias del siglo XX, esas que, de acuerdo con Benjamin y otros autores de la Escuela de Frankfurt, poseen el signo de la catástrofe o de la barbarie, atendiendo a una de las preguntas centrales que planteasen Adorno y Horkheimer (2007, p. 11) en el prólogo a la primera edición alemana de su Dialéctica de la Ilustración en 1944: "comprender por qué la humanidad en lugar de alcanzar un estado verdaderamente humano, se hunde en una nueva forma de barbarie". Pues esa puede ser, al fin y al cabo, una preocupación que justifique nuestra labor como docentes, la pertinencia de incluir la Historia y, de manera más amplia, las Ciencias Sociales en los currículos escolares.

\section{INTERPRETAR LAS VIOLENCIAS DEL SIGLO XX}

\subsection{Cronologías y debates historiográficos}

Uno de los cambios que nos parece fundamentales que incorpora la propuesta de Enzo Traverso es el de tomar distancia respecto de las batallas ideológicas que configuraron los debates historiográficos del siglo XX, pero sin distanciarse acríticamente de ellos, sino todo lo contrario. No obstante en su obra la historia militante del siglo XX se transforma en una historia crítica en la que las viejas diferencias entre las izquierdas políticas resulta solamente un sustrato que no parece insalvable como forma de tender puentes hacia otras interpretaciones. En este sentido, incorpora algunos de los planteamientos que un abultado número de historiadores y profesorado se niega todavía vehemente a incluir, y que no es otro que el cambio de ciclo histórico que significó de forma simbólica la caída del muro de Berlín en 1989. Aunque sin caer, advierte, en un "posmodernismo ingenuo $^{8 "}$ (Traverso, 2017, p. 20). Nos parece que ya va siendo hora de abordar algunas transformaciones que resultan irreversibles en el orden cultural, entre otras esferas de nuestra existencia, incluidas las interpretaciones y formas de acercarse al pasado. Siguiendo la metáfora de Koselleck en el paso de la crisis de las sociedades del Antiguo Régimen al periodo de la Restauración en el siglo XIX, Traverso considera que atravesamos una "época bisagra" o "era de transición" (Sattelzeit), la cual "ha modificado la manera de pensar y de escribir la historia del siglo XX" (Ibídem, p. 15.). Reflexión que se puede hacer extensa a otros periodos históricos. Entre otras grandes cuestiones, la propia categoría de Occidente se ve cuestionada frente a las transformaciones que plantean la "historia global" o fenómenos como la globalización, por no hablar de otros grandes temas o preocupaciones como pueden ser la idea de progreso (linealidad de la Historia) o la de modernidad (y su imbricación con el nuevo contexto cultural o los nuevos regímenes de verdad en el siglo XXI). De modo que, este nuevo contexto exige nuevas interpretaciones, así como, probablemente también, nuevas periodizaciones, lo que generará irremediablemente nuevos debates historiográficos. Esta continua re-interpretación y nuevas miradas del pasado es, desde nuestro punto de vista, lo que enriquece nuestro campo de estudio. Pero también nos exige, como docentes e investigadores, una alerta continuada a la hora de intentar transmitirlos, dentro de ese proceso alquímico al que hacíamos mención en la introducción.

Uno de los primeros, de acuerdo con Traverso, en comprender estos cambios fue el historiador marxista británico Eric Hobsbawm, quien en su obra sobre la Historia del siglo XX (1994) diferenció un siglo XX "corto" -el que transcurre desde el inicio de la Gran Guerra hasta la caída del muro- de un siglo XIX "largo" -entre la Revolución francesa y la Primera Guerra Mundial ${ }^{9}$-. En palabras del

\footnotetext{
${ }^{8}$ Para Traverso, la historia exige continuamente un "esfuerzo de distanciamiento crítico" (Traverso, 2007, p. 32). Mientras que, por otro lado, el giro lingüístico (linguistic turn): "ha permitido establecer una dialéctica nueva entre realidad e interpretación, entre textos y contextos, redefiniendo las fronteras de la Historia intelectual y cuestionando de manera saludable el estatuto del historiador" (Ibidem, p. 56). Estamos completamente de acuerdo con él.

${ }^{9}$ El Título original de la obra es: La era de los extremos. El siglo veinte corto, 1914-1991 (The Age of Extremes. The short 20th century, 1914-1991).
} 
italiano: "cualquier nueva interpretación del mundo contemporáneo no podrá escapar a una confrontación con su perspectiva"; y lo que nos parece todavía más destacable, el conjunto de su obra supone en líneas generales un fuerte: "contrapunto al consenso liberal en torno a una visión del capitalismo como orden natural del mundo" (Traverso, 2017, p. 35). Necesario para abordar una configuración de la historia desde un punto de vista crítico, tal y como planteé en el epígrafe anterior. Considero que no es preciso destacar el valor didáctico de la obra de Hobsbawm, y en especial su tetralogía sobre el siglo XIX, la cual precede a la obra citada. En efecto, entre 1962 y 1987 publicó: La era de la revolución, 1789-1848, La era del capital, 1848-1875 y La era del imperialismo, 18751914 , las cuales podríamos considerar que abordan las grandes cuestiones del siglo XIX, junto con otras obras también muy accesibles tales como Naciones y nacionalismo desde 1780 (1990), o Cómo cambiar el mundo. Marx y el marxismo. 1840-2011 (2011), que servía como colofón a su particular visión de una historia que no renunciaba de su herencia marxista alejada de las viejas ortodoxias estalinianas del siglo XX. Bien pueden estructurar estas lecturas los materiales didácticos para configurar la programación de un curso sobre historia contemporánea, mientras que, al mismo tiempo, la percepción de Hobsbawm por parte de algunos académicos en activo como "desfasada" nos debe poner sobre la alerta de que la historia como campo de batalla, a pesar de la visión aparentemente neutral y cientifista de algunos docentes, es una realidad muy presente en los centros de enseñanza secundaria y universitaria. Pues bien, para los que a Hobsbawm les parezca un autor demasiado "radical" (o incluso "desfasado") -pocos dudaríamos que central en lo que a interpretaciones o valoraciones globales de la historia contemporánea se refiere-, Traverso decide ir un paso más allá e indica, siguiendo algunos estudios decoloniales, que la propuesta del británico, a pesar de todo: "queda presa de un horizonte eurocéntrico" (Traverso, 2017, p. 49), especialmente al relativizar el alcance de las revoluciones coloniales. Pero ¿Es cierta esta afirmación? ¿No resulta quizá un tanto severo?

Probablemente se refiere la enunciación de Traverso a esa dificultad que encontramos para explicar el alcance de la experiencia colonial en el imaginario europeo, casi borrada de los currículos escolares, sin hacer una crítica a los conceptos de civilización o progreso como elementos centrales del proyecto de la Ilustración y de la propia modernidad, tal y como reflexionaron ampliamente los filósofos de Frankfurt, y de la que el propio Hobsbawm fue partícipe. Como anécdota contaré la reticencia que muestran algunos de mis alumnos y algunas de mis alumnas a la hora de narrar la participación de los europeos, y en concreto también de los españoles y portugueses, en el comercio de esclavos durante la Edad Moderna e inicios de la Edad Contemporánea. Me consta que muchos profesores abordan esta cuestión echándoles la culpa a otros países que, efectivamente, se lucraron más de este comercio, como si eso fuese suficiente para exculpar la génesis de algunas de las problemáticas del mundo actual, en el que la situación en los países del Tercer Mundo emerge mostrándonos nuevas formas de barbarie, en pleno siglo XXI, vinculados a procesos de tal calado como el de la industrialización ${ }^{10}$; o, en su génesis, el concepto de 〈acumulación originaria ${ }^{11}$ ). También la reticencia a aceptar que la abolición de la esclavitud en nuestro país no se produjo hasta el siglo XIX ${ }^{12}$. Considero que subyace en su inconsciente cierta sensación de culpa como uno de los

\footnotetext{
${ }^{10}$ Sobre este proceso y sus interpretaciones, de nuevo, en torno al "paradigma burgués", resultan interesantes las apreciaciones de Ellen Meiksins Wood (2018 [1991]) en su obra La prístina cultura del capitalismo. Un ensayo histórico sobre el Antiguo Régimen y el Estado Moderno, recientemente traducido.

${ }^{11} \mathrm{Al}$ respecto, es muy útil cómo aborda todos estos elementos el libro de texto de Elena Cabezalí y Candelas González (2011), Historia del mundo contemporáneo, de la editorial Akal.

${ }^{12}$ Formalmente se abolió en 1837 todo tipo de esclavitud, aunque para esa fecha ya no había esclavos en la Península, al menos desde 1766. No obstante, Cuba y Puerto Rico quedaron exentas de cumplir la norma. La prohibición de la esclavitud en Puerto Rico llegó en 1873, tras su independencia. Mientras que en Cuba se retrasaría hasta 1886. Es interesante, al respecto, el debate provocado en los medios de comunicación españoles las declaraciones del presidente de México, Andrés Manuel López Obrador, sobre las acciones de los españoles en la conquista y colonización de este país, o los continuos intentos por revisar y relativizar la leyenda negra española. Sin duda un campo abonado para plantear debates en el aula. Sobre revisionismos en el siglo XX hablaremos enseguida.
} 
momentos en los que se produce esa sensación de extrañamiento por el que las sociedades del presente nos sentimos partícipes de nuestro pasado, con todo lo que ello significa. Después de todo, la historia no es ese compartimento estanco que ya no existe, sino que vuelve, e incluso tiene la capacidad de perturbarnos, tal y como planteó Walter Benjamin. He podido observar reacciones similares a raíz de la explicación de algunas de las acciones de los europeos en África, en concreto el triste genocido de Leopoldo II de Bélgica en el Congo, cuyas cifras se estiman en hasta ocho millones de personas. Trataba de prepararles, siguiendo el hilo argumental del curso, para los debates en torno al Holocausto, como idea central de lo que Hobsbawm denominó "era de la catástrofe" (1914-1945). Periodo que Traverso aborda bajo el epíteto de Guerra Civil Europea. ¿Qué hay detrás de este otro concepto que pone título a nuestro artículo?

\subsection{La Guerra civil europea}

Traverso aborda este concepto en su obra A Sangre y Fuego. De la guerra civil europea (19141945). En ella indica que: "existe una tendencia (...) a asociar la idea de (guerra civil europea> al historiador alemán Ernst Nolte" (Traverso, 2009, p. 30); por ser este quien lo ha abordado de manera más sistemática. No obstante, el honor de su formulación se lo deberíamos al pintor alemán Franz Marc en una carta antes de ser abatido en el frente de Verdún durante la Gran Guerra. Consideramos que tampoco es necesario hacer demasiadas aclaraciones acerca de la figura del historiador alemán Ernst Nolte, así como de su influencia a la hora de generar una corriente histórica denominada como "revisionismo histórico", la cual se ha ido extendiendo progresivamente a otros países, con especial mención, por nuestra cercanía con estos hechos, a España y los acontecimientos en torno a la Guerra Civil y el franquismo, y a pesar de las reticencias del propio Traverso a la hora de utilizar este concepto con connotaciones peyorativas ${ }^{13}$. Nolte interpreta el siglo XX como "una época dominada por un conflicto radical (...) entre revolución y contrarrevolución, comunismo y fascismo" (Ibídem, p. 32) a los que define bajo el epíteto de totalitarismos. De modo que, sin negar el "genocidio de los judíos como «la masacre más terrible de la historia universal»", la considera más bien "como un crimen derivado, una simple 〈imitación〉 del 〈genocidio〉 bolchevique". Desvelando así, en opinión de Traverso: "la verdadera fuente del mal, en el bolchevismo" (Ibídem, p. 33). Nolte deja esta idea clara desde la introducción de su obra. En ella, en referencia a lo que define como era del fascismo, considera que "para poder dilucidar el carácter de dicho periodo no basta con estudiar únicamente el fascismo", sino que además: "es necesario examinar la condición más elemental para la existencia de éste, el bolchevismo o comunismo soviético" (Nolte, 1994, p. 14).

La Guerra civil europea se configuraría, de este modo, como un conflicto ideológico entre totalitarismos, el cual se va reproduciendo en numerosos frentes como puede ser el caso español, y del que resultará vencedor un liberalismo redimido en este paréntesis de la modernidad, marcada por el signo de la barbarie o de la catástrofe, tal y como veíamos anteriormente. Interpretación que ha provocado, siguiendo a Traverso, un eclipse de la memoria del comunismo, así como de otras utopías de este periodo: "la idea misma de revolución ha sido criminalizada, inmediatamente reenviada a la categoría de 〈comunismo〉 y así archivada en el capítulo de 〈totalitarismo〉 de la Historia del siglo XX" (Traverso, 2007, p. 75). Aquí vemos las primeras grietas y posibles críticas a este análisis, ya que en España, por ejemplo, este paréntesis duró más de tres décadas. La explicación de las tesis de Nolte daría para más, puesto que está llena de matices. No obstante, se nos va a permitir esta simplificación con el objetivo de poder exponer nuestras ideas. En efecto, dicha simplificación constituye a nuestro modo de entender una de las explicaciones más populares de este periodo en los años recientes a la hora de abordar las asignaturas relacionadas con la Historia del Mundo

\footnotetext{
${ }^{13}$ En Alemania, la polémica tesis de este historiador dio pie a la denominada «querella de los historiadores〉, entre 1986 y 1987. Su principal detractor en este debate público fue Habermas. En el fondo, subyacía, al igual que en otros debates posteriores sostenidos en Alemania en los últimos años, la idea de considerar la singularidad de los crímenes del nazismo, o bien inscribirlos en procesos históricos de carácter más amplio.
} 
Contemporáneo, especialmente en las enseñanzas no universitarias ${ }^{14}$. El propio Hobsbawm, cuyo relato dista mucho de estas interpretaciones, en su Historia del siglo XX (o La era de los extremos) citada anteriormente- describe la Segunda Guerra Mundial como un conflicto internacional entre los aliados de la Ilustración, entre los que se incluye el socialismo soviético y el liberalismo, frente a su antítesis, es decir, el fascismo. Planteamiento que ha ido perdiendo fuerza frente a la explicación anterior, fruto del nuevo contexto de triunfo de las ideas neoliberales en un escenario de globalización, y en el que la economía y Estado liberales son interpretados como el "fin de la historia".

Frente a este punto de vista, la explicación de Traverso se configura como lo que nos parece una receta adecuada frente a revisionismos históricos, pero también, a nuestro modo de ver, mucho más sutil e interesante que lo expuesto por otros historiadores de izquierdas en periodos anteriores o, en todo caso, más ajustada dentro de los nuevos parámetros interpretativos expuestos con anterioridad. En su obra, le da un giro de tuerca a las famosas tesis de Nolte y enuncia este concepto definiéndolo como ciclo histórico, esto es, un periodo que transcurre entre el inicio de la Gran Guerra y el final de la Segunda Guerra Mundial, y en el que Europa conoció una insólita acumulación de conflictos, más allá de ese enfrentamiento titánico entre liberalismo y totalitarismo o Ilustración y nihilismo. De este modo, la guerra civil europea se presenta desde la introducción como un ciclo de: "guerras «clásicas〉 entre estados, revoluciones, guerras civiles, guerras de liberación nacional, genocidios, enfrentamientos violentos surgidos de divisiones de clases, nacionales, religiosas, políticas e ideológicas" (Traverso, 2009, p. 30). Y en ella analiza, configurado una suerte de Libro de los pasajes, famosa obra inacabada de Walter Benjamin en la que trabajó desde 1927 hasta su muerte, una anatomía de la guerra civil europea que va más allá de una restitución de la memoria comunista en el siglo XXI, tal y como se podría pensar a simple vista. Siguiendo de nuevo a los filósofos de Frankfurt, entiende este periodo como una regresión del proceso de civilización. Regresión que encuentra sus antecedentes, por ejemplo, en los enfrentamientos coloniales que, en el siglo XIX, preparan este periodo, marcados por el signo del avance de la industrialización y el capitalismo. La guerra civil europea también define, por tanto, los "logros del proceso de civilización" (reproducimos la cita por su interés): "La monopolización estatal de las armas, la racionalidad administrativa y productiva, la división del trabajo, la fragmentación de las tareas, el autocontrol de las pulsiones, la irresponsabilización ética de los actores sociales, la separación espacial entre ejecutores y víctimas" (Ibídem, p. 83).

De lo que resultó un conflicto de aniquilación, el cual tiene muchos y ricos vectores de análisis, desde el acontecimiento central en el que desemboca, como es la Shoah, a las acciones criminales de la wehrmacht y las SS, el ejército rojo, o los bombardeos aliados sobre Dresde y otras ciudades alemanas, culminando en el lanzamiento de sendas bombas atómicas sobre Hiroshima y Nagasaki, así como un largo y doloroso etcétera. En otras palabras, un conflicto que define unas vastísimas zonas grises. De este modo, los planteamientos de Traverso pueden funcionar como una receta, al fin y al cabo, para combatir no solamente las posturas apologéticas del fascismo, sino también las del propio relato liberal sobre este periodo. Y, desde nuestro punto de vista, finalmente, una buena fórmula para abordar la explicación de un periodo histórico tan complejo, el cual puede ser presentado precisamente a través de sus controversias historiográficas y puntos negros. Ello nos permitiría no sólo abordar los contenidos de la materia de manera más precisa y actualizada, sino también presentar un campo de estudio, como es la historia, repleto de preguntas, no acabado, o en constante construcción, así como susceptible siempre de ser reinterpretado. Idea que alberga también los planteamientos teórico-metodológicos presentados por plataformas como Fedicaria para el análisis, estudio y explicación de las Ciencias Sociales, en este caso la Historia ${ }^{15}$. En su famosa conferencia

\footnotetext{
${ }^{14} \mathrm{Al}$ respecto, es especialmente poco apropiada - o con un enfoque opuesto al que defendemos en este artículo- la forma de abordar todos estos elementos que hace el libro de texto de Luis E. Otero (2008), Historia del mundo contemporáneo, de la editorial SM.

${ }^{15}$ Respecto a esta forma de entender y explicar la didáctica de las Ciencias Sociales, pueden consultarse diferentes propuestas en Mainer (2001).
} 
publicada en 1967 ("La educación después de Auschwitz"), Adorno señalaba que "en el principio mismo de civilización está instalada la barbarie", al mismo tiempo que pedía que la educación debía proponerse como objetivo central que estos fenómenos no se repitiesen. En pleno siglo XXI, estas premisas continúan teniendo completa vigencia, a pesar de la opinión de autores como Nolte, quien considera que: "el temor a que se repitan ciertos sucesos, carece de todo fundamento" (Nolte, 1994, p. 22).

\subsection{Contenidos, objetivos y competencias clave}

Por tanto, los contenidos que engloba nuestra propuesta didáctica, tal y como mencionábamos en la introducción, son principalmente los recogidos en el Bloque 5 del currículo para la ESO y el Bachillerato. En las siguientes tablas éstos aparecen relacionados con los criterios de evaluación, estándares de aprendizaje evaluables, según la legislación vigente, de manera más precisa.

TABLA 1. Contenidos, criterios y estándares para la ESO. Elaboración propia a partir del Real Decreto 1105/2014, de 26 de diciembre, por el que se establece el currículo básico de la ESO y del Bachillerato.

\begin{tabular}{|c|c|c|}
\hline Contenidos & Criterios de evaluación & $\begin{array}{l}\text { Estándares de aprendizaje } \\
\text { evaluables. }\end{array}$ \\
\hline $\begin{array}{l}\text { Bloque 4. El imperialismo del } \\
\text { siglo XIX y la Primera Guerra } \\
\text { Mundial: } \\
\text { "La Gran Guerra" (1914.1919), o } \\
\text { Primera Guerra Mundial. La } \\
\text { Revolución Rusa. } \\
\text { Las consecuencias de la firma de } \\
\text { la Paz. }\end{array}$ & $\begin{array}{l}\text { 3. Conocer los principales } \\
\text { acontecimientos de la Gran } \\
\text { Guerra, sus interconexiones con la } \\
\text { Revolución Rusa y las } \\
\text { consecuencias de los Tratados de } \\
\text { Versalles. } \\
\text { 4. Esquematizar el origen, el } \\
\text { desarrollo y las consecuencias de } \\
\text { la Revolución Rusa. }\end{array}$ & $\begin{array}{l}\text { 3.1. Diferencia los } \\
\text { acontecimientos de los procesos } \\
\text { en una explicación histórica, de la } \\
\text { Primera Guerra Mundial. } \\
\text { 3.2. Analiza el nuevo mapa } \\
\text { político de Europa. 3.3. Describe } \\
\text { la derrota de Alemania desde su } \\
\text { propia perspectiva y desde la de } \\
\text { los aliados. } \\
\text { 4.1. Contrasta algunas } \\
\text { interpretaciones del alcance de la } \\
\text { Revolución Rusa en su época y en } \\
\text { la actualidad. }\end{array}$ \\
\hline $\begin{array}{l}\text { Bloque 5. La época de } \\
\text { "Entreguerras" (1919-1945): } \\
\text { La difícil recuperación de } \\
\text { Alemania. } \\
\text { El fascismo italiano. } \\
\text { El crash de } 1929 \text { y la gran } \\
\text { depresión. } \\
\text { El nazismo alemán. } \\
\text { La II República en España } \\
\text { La guerra civil española }\end{array}$ & $\begin{array}{l}\text { 1. Conocer y comprender los } \\
\text { acontecimientos, hitos y procesos } \\
\text { más importantes del Período de } \\
\text { Entreguerras, o las décadas } \\
\text { 1919.1939, especialmente en } \\
\text { Europa. } \\
\text { 2. Estudiar las cadenas causales } \\
\text { que explican la jerarquía causal en } \\
\text { las explicaciones históricas sobre } \\
\text { esta época, y su conexión con el } \\
\text { presente. } \\
\text { 3. Analizar lo que condujo al auge } \\
\text { de los fascismos en Europa. }\end{array}$ & $\begin{array}{l}\text { 1. Conocer los principales hechos } \\
\text { de la Segunda Guerra Mundial. } \\
\text { 2. Entender el concepto de "guerra } \\
\text { total". } \\
\text { 3. Diferenciar las escalas } \\
\text { geográficas en esta guerra: } \\
\text { Europea y Mundial. } \\
\text { 4. Entender el contexto en el que } \\
\text { se desarrolló el Holocausto en la } \\
\text { guerra europea y sus } \\
\text { consecuencias. }\end{array}$ \\
\hline $\begin{array}{l}\text { Bloque 6. Las causas y } \\
\text { consecuencias de la Segunda } \\
\text { Guerra Mundial (1939-1945): } \\
\text { Acontecimientos previos al } \\
\text { estallido de la guerra: expansión } \\
\text { nazi y "apaciguamiento". De } \\
\text { guerra europea a guerra mundial. } \\
\text { El Holocausto. }\end{array}$ & $\begin{array}{l}\text { 1. Conocer los principales hechos } \\
\text { de la Segunda Guerra Mundial. } \\
\text { 2. Entender el concepto de "guerra } \\
\text { total". } \\
\text { 3. Diferenciar las escalas } \\
\text { geográficas en esta guerra: } \\
\text { Europea y Mundial. }\end{array}$ & $\begin{array}{l}\text { 1.1. Elabora una narrativa } \\
\text { explicativa de las causas y } \\
\text { consecuencias de la Segunda } \\
\text { Guerra Mundial, a distintos } \\
\text { niveles temporales y geográficos. } \\
\text { 2.1. Reconoce la jerarquía causal } \\
\text { (diferente importancia de unas }\end{array}$ \\
\hline
\end{tabular}




\begin{tabular}{|c|c|c|}
\hline $\begin{array}{l}\text { La nueva geopolítica mundial: } \\
\text { "guerra fría" y planes de } \\
\text { reconstrucción post-bélica. }\end{array}$ & $\begin{array}{l}\text { 4. Entender el contexto en el que } \\
\text { se desarrolló el Holocausto en la } \\
\text { guerra europea y sus } \\
\text { consecuencias. }\end{array}$ & $\begin{array}{l}\text { causas u otras según las distintas } \\
\text { narrativas). } \\
\text { 3.1. Da una interpretación de por } \\
\text { qué acabó antes la guerra } \\
\text { "europea" que la "mundial". } \\
\text { 3.2. Sitúa en un mapa las fases del } \\
\text { conflicto. } \\
\text { 4.1. Reconoce la significación del } \\
\text { Holocausto en la historia mundial. }\end{array}$ \\
\hline
\end{tabular}

TABLA 2. Contenidos, criterios y estándares para Bachillerato. Elaboración propia a partir del Real Decreto 1105/2014, de 26 de diciembre, por el que se establece el currículo básico de la ESO y del Bachillerato.

\begin{tabular}{|c|c|c|}
\hline Contenidos & Criterios de evaluación & $\begin{array}{l}\begin{array}{l}\text { Estándares de } \\
\text { evaluables }\end{array} \\
\end{array}$ \\
\hline $\begin{array}{l}\text { Bloque 4. La dominación } \\
\text { europea del mundo y la I } \\
\text { Guerra Mundial: } \\
\text { La I Guerra Mundial: causas, } \\
\text { desarrollo y consecuencias. }\end{array}$ & $\begin{array}{l}\text { 5. Distinguir los acontecimientos } \\
\text { que conducen a la declaración de } \\
\text { las hostilidades de la Primera } \\
\text { Guerra Mundial, desarrollando } \\
\text { sus etapas y sus consecuencias. } \\
\text { 6. Localizar fuentes primarias y } \\
\text { secundarias (en bibliotecas, } \\
\text { Internet, etc.) y extraer } \\
\text { información de interés, valorando } \\
\text { críticamente su fiabilidad. } \\
\text { 7. Utilizar el vocabulario histórico } \\
\text { con precisión, insertándolo en el } \\
\text { contexto histórico de finales del } \\
\text { siglo XIX y comienzos del XX. }\end{array}$ & $\begin{array}{l}\text { 5.1. Identifica a partir de fuentes } \\
\text { históricas o historiográficas las } \\
\text { causas de la I Guerra Mundial. } \\
\text { 5.2. Comenta símbolos } \\
\text { conmemorativos vinculados a la I } \\
\text { Guerra Mundial. } \\
\text { 6.1. Analiza y explica las distintas } \\
\text { etapas de la Gran Guerra a partir } \\
\text { de mapas históricos. } \\
\text { 7.1. Extrae conclusiones de } \\
\text { gráficos e imágenes sobre las } \\
\text { consecuencias de la I Guerra } \\
\text { Mundial. }\end{array}$ \\
\hline $\begin{array}{l}\text { Bloque 5. El periodo de } \\
\text { Entreguerras. La Segunda } \\
\text { Guerra Mundial y sus } \\
\text { consecuencias: } \\
\text { Economía, sociedad y cultura de } \\
\text { la época: los años veinte. } \\
\text { La revolución rusa, la formación y } \\
\text { desarrollo de la URSS. } \\
\text { Tratados de Paz y reajuste } \\
\text { internacional: la Sociedad de } \\
\text { Naciones. } \\
\text { Estados Unidos y la crisis de } \\
\text { 1929: la Gran Depresión y el New } \\
\text { Deal. } \\
\text { Europa Occidental: entre la } \\
\text { reconstrucción y la crisis. } \\
\text { Los fascismos europeos y el } \\
\text { nazismo alemán. } \\
\text { Las relaciones internacionales del } \\
\text { período de Entreguerras, virajes } \\
\text { hacia la guerra. } \\
\text { Orígenes del conflicto y } \\
\text { características generales. } \\
\text { Desarrollo de la Guerra. } \\
\text { Consecuencias de la Guerra. }\end{array}$ & $\begin{array}{l}\text { 1. Reconocer las características } \\
\text { del período de Entreguerras } \\
\text { insertándolas en r los } \\
\text { correspondientes aspectos } \\
\text { políticos, económicos, sociales o } \\
\text { culturales. } \\
\text { 2. Esquematizar el desarrollo de la } \\
\text { Revolución Rusa de } 1917 \\
\text { reconociendo sus etapas y sus } \\
\text { protagonistas más significativos y } \\
\text { estableciendo sus consecuencias. } \\
\text { 3. Identificar los Tratados de Paz } \\
\text { de la I Guerra Mundial } \\
\text { estableciendo como una } \\
\text { consecuencia el surgimiento de la } \\
\text { Sociedad de Naciones. } \\
\text { 4. Explicar la Gran Depresión } \\
\text { describiendo los factores } \\
\text { desencadenantes y sus influencias } \\
\text { en la vida cotidiana. } \\
\text { 5. Reconocer la trascendencia de } \\
\text { los fascismos europeos como } \\
\text { ideologías que condujeron al } \\
\text { desencadenamiento de conflictos }\end{array}$ & $\begin{array}{l}\text { 1.1. Explica las características del } \\
\text { Periodo Entreguerras a partir de } \\
\text { manifestaciones artísticas y } \\
\text { culturales de comienzos del siglo } \\
\text { XX. } \\
\text { 2.1. Identifica y explica algunas } \\
\text { de las causas de la Revolución } \\
\text { Rusa de } 1917 \text {. } \\
\text { 2.2. Compara la Revolución Rusa } \\
\text { de Febrero de } 1917 \text { con la de } \\
\text { Octubre de } 1917 \text {. } \\
\text { 3.1. Explica los acuerdos de los } \\
\text { Tratados de Paz de la I Guerra } \\
\text { Mundial y analiza sus } \\
\text { consecuencias a corto plazo. } \\
\text { 3.2. Analiza el papel que juega la } \\
\text { Sociedad de Naciones en las } \\
\text { relaciones internacionales, a partir } \\
\text { de fuentes históricas. } 4.1 . \\
\text { Interpreta imágenes de la Gran } \\
\text { Depresión. } \\
\text { 4.2. Comenta gráficas que } \\
\text { explican la crisis económica de } \\
\text { 1929. }\end{array}$ \\
\hline
\end{tabular}




\begin{tabular}{|c|c|c|}
\hline $\begin{array}{l}\text { El Antisemitismo: el Holocausto. } \\
\text { Preparación de la Paz y la ONU. }\end{array}$ & $\begin{array}{l}\text { en el panorama europeo del } \\
\text { momento. } \\
6 \text {. Establecer las etapas del } \\
\text { desarrollo de la II Guerra } \\
\text { Mundial, distinguiendo las que } \\
\text { afectaron a Europa y las que } \\
\text { afectaron a Estados Unidos y } \\
\text { Japón. } \\
\text { 7. Analizar el papel de la guerra } \\
\text { mundial como elemento de } \\
\text { transformación de la vida } \\
\text { cotidiana. } \\
\text { 8. Obtener y seleccionar } \\
\text { información escrita y gráfica } \\
\text { relevante, utilizando fuentes } \\
\text { primarias o secundarias, relativa } \\
\text { tanto al período de Entreguerras } \\
\text { como a la II Guerra Mundial y la } \\
\text { postguerra. }\end{array}$ & $\begin{array}{l}\text { 5.1. Compara el fascismo italiano } \\
\text { y el nazismo alemán. } \\
\text { 5.2. Distingue símbolos de los } \\
\text { fascismos europeos de la Primera } \\
\text { Mitad del siglo XX. } \\
\text { 5.3. Analiza a partir de diferentes } \\
\text { fuentes contrapuestas las } \\
\text { relaciones internacionales } \\
\text { anteriores al estallido de la II } \\
\text { Guerra Mundial. } \\
\text { 6.1. Identifica y explica las causas } \\
\text { desencadenantes de la II Guerra } \\
\text { Mundial a partir de fuentes } \\
\text { históricas. } \\
\text { 6.2. Explica las etapas de la II } \\
\text { Guerra Mundial tanto en el frente } \\
\text { europeo como en la guerra del } \\
\text { Pacífico. } \\
\text { 6.3. Analiza el desarrollo de la II } \\
\text { Guerra Mundial a partir de mapas } \\
\text { históricos. } \\
\text { 7.1. Describe las consecuencias de } \\
\text { la II Guerra Mundial. } \\
\text { 8.1. Analiza imágenes que } \\
\text { explican el Holocausto llevado a } \\
\text { cabo por la Alemania Nazi. } \\
\text { 8.2. Sintetiza textos que explican } \\
\text { la intervención de la ONU en las } \\
\text { relaciones internacionales y } \\
\text { asuntos de descolonización. }\end{array}$ \\
\hline
\end{tabular}

En cuanto a los objetivos y competencias clave, pueden ser tenidos en consideración los siguientes, todos ellos extraídos del currículo oficial:

- Para la ESO:

- a) Conocer y ejercer sus derechos en el respeto a los demás practicar la tolerancia (...) como valores comunes de una sociedad plural y prepararse para el ejercicio de una ciudadanía democrática

○ d) (...) rechazar la violencia, los prejuicios de cualquier tipo (...) y resolver pacíficamente los conflictos

$\circ$ j) Conocer, valorar y respetar los aspectos básicos de la cultura y la historia propias y de los demás, así como el patrimonio artístico y cultural

- Para Bachillerato:

- a) Ejercer la ciudadanía democrática, desde una perspectiva global, y adquirir una conciencia cívica responsable (...) que fomente la corresponsabilidad en la construcción de una sociedad justa y equitativa.

o b) Consolidar una madurez personal y social que les permita actuar de forma responsable y autónoma y desarrollar su espíritu crítico. Prever y resolver pacíficamente los conflictos personales, familiares y sociales.

$\circ$ h) Conocer y valorar críticamente las realidades del mundo contemporáneo, sus antecedentes históricos y los principales factores de su evolución. Participar de forma solidaria en el desarrollo y mejora de su entorno social.

- Competencias clave (para ambas etapas):

$\circ$ Aprender a aprender (CPAA) 


\section{- Competencias sociales y cívicas (CSC) \\ - Conciencia y expresiones culturales (CEC)}

Asimismo, como elemento transversal, cabe destacar la prevención de la xenofobia y el racismo, así como cualquier forma de discriminación por motivos de sexo, orientación sexual o clase social.

No obstante, lo que nos parece más importante, es referenciar la complejidad didáctica a la que hacíamos mención en la introducción, así como poner de manifiesto la utilidad del concepto de "Guerra civil europea" para explicar este periodo, especialmente en cursos de la ESO en los que conflictos asociados, de acuerdo con la interpretación de Enzo Traverso, como la Guerra civil española, aparecen directamente relacionados. Sirve de este modo para introducir las particularidades de la Historia de España dentro de su contexto europeo.

A continuación pasaremos a relatar la aplicación práctica de nuestra propuesta tomando como ejemplo el trabajo de campo desarrollado en dos cursos de $1^{\circ}$ de Bachillerato durante el año académico 2018-2019 en la Escuela de Arte de Salamanca. Experiencia didáctica a partir de la cual reflexionaremos, finalmente, sobre los resultados, utilidad y limitaciones de la misma.

\section{EXPERIENCIA DIDÁCTICA}

Inicialmente, la experiencia fue propuesta como un Proyecto para realizar una Exposición de Arte sobre la primera mitad del siglo XX en Europa en base a las características del alumnado (modalidad Artes). Para ello, cada alumno/a debía elaborar una obra (pintura, etc.) en la que expresase qué le sugería este periodo, así como su propia interpretación del significado del mismo, retratando su punto de vista en torno a la guerra y la violencia tanto a lo largo de la historia como en el presente (problematizar el presente/pensar históricamente). Como elemento motivacional, se acordó reservar una de las cuatro sesiones semanales (la de los viernes) para que pudiesen desarrollar esta parte del trabajo, siempre que el resto de sesiones semanales se avanzasen contenidos y se trabajase de forma apropiada. El Proyecto se desarrolló durante el segundo trimestre, preparándose la Exposición tratando de hacerla coincidir con la semana cultural (finales del segundo trimestre) o, si los resultados eran óptimos, llevándola a la Facultad de Geografía e Historia de la Universidad de Salamanca, con cuyo decanato se acordó la cesión de un espacio reservado a exposiciones de carácter cultural. La elección del título de la Exposición se hizo conforme a la reflexión en torno a algunas de las denominaciones sobre este periodo, las cuales fueron explicadas por el profesor, para relacionar contenidos y la actividad que se estaba desarrollando: "Era de las catástrofes" o "Era de los extremos" (Eric Hobsbawm), "Guerra civil Europea" (término acuñado por el pintor Franz Marc), y "A Sangre y Fuego" (título de la obra de Traverso). Se trataba de ir introduciendo de este modo al alumnado en los debates y distintas interpretaciones existentes desarrolladas en los epígrafes anteriores, al mismo tiempo que se iba explicando la materia y se implicaba al alumnado en el desarrollo de la actividad programada. Ambos grupos acordaron titular la Exposición "Guerra Civil Europea". Mientras que, por otro lado, a lo largo de las sesiones de este segundo trimestre, se fueron analizando, como materiales adicionales a los presentes en el libro de texto, diversos textos que el profesor planteó para guiar la exposición y para que cada alumno/a pudiese confeccionar sus trabajos. Los textos seleccionados fueron los siguientes:

- Texto 1. "La era de los extremos produce su imaginario de horror, detrás del cual se esconde un universo de sufrimiento, pero también de experiencias sociales, de culturas compartidas, de ideas y de luchas que podemos explorar a través del concepto de « guerra civil europea»" (Enzo Traverso).

- Texto 2. "A través de él intentaremos captar el sentido de una época de guerras y revoluciones en la que la simbiosis entre cultura, política y violencia modeló profundamente las mentalidades, las ideas, las representaciones y las prácticas de sus autores, la cual no se puede reducir a los horrores del totalitarismo" (Enzo Traverso) 
- Texto 3. "Durante la primera mitad del siglo XX, Europa conoció una insólita acumulación de conflictos: guerras «clásicas» entre estados, revoluciones, guerras civiles, guerras de liberación nacional, genocidios, enfrentamientos violentos surgidos de divisiones de clases, nacionales, religiosas, políticas e ideológicas" (Enzo Traverso)

- Texto 4. "Entre ellos la Shoah, que significa catástrofe en hebreo. Un genocidio perpetrado en el corazón de la Segunda Guerra Mundial pero que, siguiendo a autores como Enzo Traverso, no puede ser simplemente deducido a su lógica interna" (Escuela de Arte de Salamanca)

- Texto 5. "Numerosos observadores contemporáneos y, en las huellas de éstos, numerosos historiadores han intentado restituir el sentido de esta era turbulenta colocándola bajo el signo de una «guerra civil europea». El carácter sintético y la fuerza evocadora de esta fórmula le han asegurado cierto éxito, pero su situación sigue siendo vaga e incierta" (Enzo Traverso)

- Texto 6. "Su inventor fue el pintor alemán Franz Marc y, a partir de él, numerosos historiadores de distintas tendencias ideológicas han confrontado este concepto de muy diferente manera. En esta exposición nos disponemos a dar nuestro propio punto de vista sobre este periodo, utilizando el arte como elemento de comunicación y Memoria para que los sucesos más terribles de nuestro pasado no vuelvan a sucederse" (Escuela de Arte de Salamanca).

Como puede observarse, en ellos se van desarrollando los distintos elementos contenidos en el currículo, especialmente los relativos al debate historiográfico. En un primer momento el alumnado se mostró reticente, puesto que no era común que un profesor formulase los contenidos de la asignatura planteando tantas dudas, quizá dejando tanto espacio a que ellos y ellas elaborasen sus propias opiniones sobre este periodo o que construyeran mentalmente su propio relato historiográfico. Probablemente les parecía que la asignatura no ofrecía suficientes seguridades y, lo que más les preocupaba -muy a mi pesar-, era casi siempre qué era, en definitiva, lo que debían escribir en los exámenes y trabajos de evaluación.

La organización de las Unidades Didácticas para el segundo trimestre, por otro lado, fue la habitual que suele contener la mayoría de los libros de texto (con muy pocas variaciones), las cuales en la Programación didáctica aparecían establecidas del siguiente modo:

- Contenidos finales del bloque 4:

○ Unidad Didáctica 5. El mundo entre 1870 y 1914 (abordada al finalizar el primer trimestre).

- Contenidos del bloque $5^{16}$ (véase epígrafe 3.3):

- Unidad Didáctica 6. La Gran Guerra.

- Unidad Didáctica 7. Las revoluciones rusas y la formación del Estado soviético.

- Unidad Didáctica 8. La economía y la sociedad en el mundo de entreguerras.

- Unidad Didáctica 10. De la paz a la guerra: la segunda guerra mundial.

En cuanto a las dificultades de esta experiencia didáctica, lo más complejo fue abordar y transmitir la idea de una historia sobre la que no existen grandes consensos, e incluso debates en los que los distintos autores se rebaten afirmando ideas a menudo contrapuestas sobre los mismos acontecimientos ${ }^{17}$. Cuestiones ante las que el alumnado a menudo se preguntaba ¿Por qué todas estas lumbreras no lograban ponerse de acuerdo?

Por lo que respecta a los resultados del Proyecto, la Exposición finalmente tuvo que limitarse al espacio del Aula, puesto que muchos alumnos y alumnas no tuvieron tiempo (o interés) en terminar sus trabajos. Con esto queremos señalar que no tratamos de mostrar una imagen apologética de nuestro trabajo, sino tan solo mostrar algunas de las posibilidades de abordar el estudio de este periodo

\footnotetext{
${ }^{16}$ Desarrollados a lo largo del segundo trimestre, de 8 de enero a 11 de abril de 2019 (48 horas lectivas aproximadas).

${ }^{17}$ Sobre diferentes propuestas didácticas y estrategias metodológicas en torno a este periodo, véanse, entre otras, las de López-García y Miralles (2018) a través del cine, Sáenz del Castillo (2017) a través de situaciones-reto, Pizarro y Cruz (2014) a través de la empatía. El elenco de ejemplos y casos didácticos para abordar este periodo es numeroso y original.
} 
desde los presupuestos presentados en el presente trabajo. En efecto, tal y como se señala desde Fedicaria y los postulados de la "didáctica crítica", además de problematizar el presente, pensar históricamente, aprender dialogando o impugnar los códigos pedagógicos y profesionales, es imprescindible educar el deseo. Por ello, tuve que ajustar también mis propias expectativas a la realidad del trabajo cotidiano en el aula. Solamente ellos y ellas podrán decir si realmente aprendieron algo durante dicho curso o si la metodología aplicada se adaptó mejor a sus necesidades educativas. En todo caso, sea como fuere, los resultados mejoraron ostensiblemente respecto de los del primer trimestre en ambos grupos y estoy seguro de que el Proyecto tuvo mucho que ver con ello.

A pesar de esto, desde mi punto de vista meramente subjetivo, considero que la experiencia fue provechosa, a pesar de ser consciente de que muchos de los elementos abordados durante esos meses solamente llegarán a ser comprehendidos más adelante, otras veces olvidados, en algunos casos ignorados. Por otro lado, por supuesto, también hubo quien pudo culminar interpretaciones artísticas de este periodo verdaderamente interesantes, las cuales me parece apropiado mostrar entre los resultados de la experiencia didáctica descrita, antes de abordar el apartado de conclusiones.

IMAGEN 1. Exposición en el aula de Historia

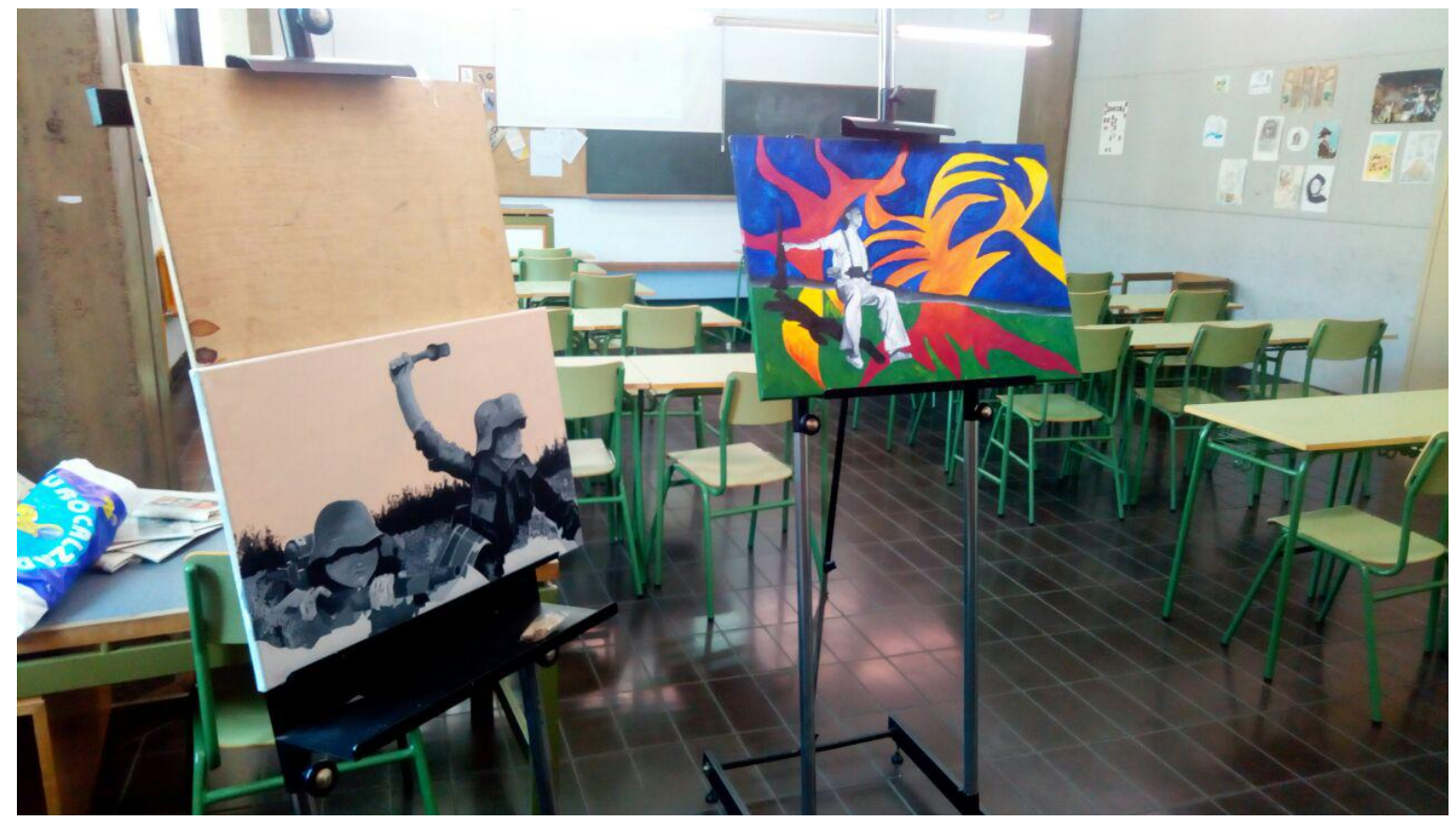

Fuente: elaboración propia.

\section{REFLEXIÓN FINAL}

No obstante, más allá de la aplicación particular de esta propuesta didáctica, sus posibles virtudes o defectos, nos parece muchísimo más útil la valoración de la docencia en Historia y otras Ciencias Sociales desde el punto de vista de los usos públicos del pasado, así como de la puesta en valor de la didáctica crítica de las ciencias sociales. La experiencia sirvió también para debatir y dialogar sobre la persistencia de cuestiones como la violencia de las guerras o el racismo en las sociedades del presente, como una forma de prevenir la xenofobia, el racismo o la discriminación por motivos de raza, sexo o clase social.

En un momento en el que el ángel de la Historia de Benjamin, si pudiese volver la mirada hacia el futuro, vería proyectadas nuevas formas de barbarie (guerras, refugiados, pobreza, destrucción del medio ambiente, etc.). Y, sobre todas ellas, especialmente en Europa y el mundo Occidental, la sombra del auge de las nuevas derechas que retornan. Imágenes, todas ellas, que nos ponen en 
relación con un futuro de carácter distópico, frente a las utopías que inundaron no sólo el siglo XX, sino toda la modernidad. Quizá sea el momento de valorar estos conocimientos como un recurso útil para prevenir la repetición o reaparición de algunos de los fenómenos más negros de nuestro pasado reciente, tal y como señaló el propio Adorno.

Como una manera de fomentar entre nuestro alumnado una visión de la historia y de la realidad que no rechace o niegue el concepto de utopía. Una educación fundada en la tolerancia y en las ciudadanías críticas.

\section{Referencias}

Horckheimer, M. y Adorno, W. (2007). Dialéctica de la Ilustración. Fragmentos filosóficos. Madrid: Akal.

Cabezalí García, E. y González González, C. (2011). Historia del mundo contemporáneo. Libro de texto. Madrid: Akal.

Cuesta, R. (2016). Materiales para comentar las tesis de Walter Benjamin Sobre el concepto de historia. Recuperado de http://grupoeculturalesagramsci.blogspot.com/2016/02/materialespara-comentar-las-tesis-de.html

Cuesta, R. (2015). La venganza de la memoria y las paradojas de la historia. Salamanca: Lulú.

Cuesta, R. (2014). Fedicaria, una peculiar forma de pensamiento crítico. Constelaciones, 6, 459-463.

Cuesta, R. y Hernández, G. (2018). El autor y su sombra. A propósito de Las lecciones de Tersites. Historia y Memoria de la Educación, 7, 683-707. DOI: 10.5944/hme.7.2018.19841.

Cuesta, R, Mainer, J., Mateos, J., Merchán, J. y Vicente., M. (2005). Didáctica crítica. Allí donde se encuentran la necesidad y el deseo. Con-Ciencia Social, 9, 17-54.

Hernández Sánchez, G. (2020). La utopía frente al Gran Hotel Abismo: reflexiones en torno a la Biografia coral de la Escuela de Frankfurt de Stuart Jeffries. Con-Ciencia Social (segunda época), 3, 127-136. DOI: 10.7203/con-cienciasocial.3.16792

Hobsbawm, E. (1989). La era del capitalismo: 1848-1875. Barcelona: Labor.

Hobsbawm, E. (1989). La era del imperio: 1875-1914. Barcelona: Labor.

Hobsbawm, E. (1991). Naciones y nacionalismos desde 1870. Barcelona: Crítica.

Hobsbawm, E. (2000). Historia del siglo XX: 1914-1991. Barcelona: Crítica.

Hobsbawm, E. (2011). La era de la revolución: 1789-1848. Barcelona: Crítica.

Hobsbawm, E. (2011). Cómo cambiar el mundo: Marx y el marxismo. 1840-2011. Barcelona: Crítica

López-García, A. y Miralles, P. (2018) La Segunda Guerra Mundial en el cine. Clasificación y transposición didáctica. En E. López Torres, C. R. García Ruíz y M. Sánchez Agustí (coords.), Buscando formas de enseñar: investigar para innovar en didáctica de las ciencias sociales (pp. 565-574). Valladolid: Asociación Universitaria de Profesorado de Didáctica de las Ciencias Sociales (AUPDCS)-Universidad de Valladolid.

Mainer, J. (2001). Discursos y prácticas para una didáctica crítica de las ciencias sociales: ideas y lineas de trabajo para transformar la enseñanza. Zaragoza: Universidad de Zaragoza

Meiksins-Wood, E. (2018). La prístina cultura del capitalismo. Un ensayo histórico sobre el Antiguo Régimen y el Estado Moderno. Madrid: Traficantes de Sueños.

Nolte, E. (1994). La guerra civil europea, 1917-1945. Nacionalsocialismo y bolchevismo. México: Fondo de Cultura Económica.

Otero, L. E. (2008). Historia del mundo contemporáneo. Libro de texto. Madrid: SM.

Pizarro, F. Cruz, P. (2014). Empatía en clase de Historia: los alumnos serán soldados de la Primera Guerra Mundial. Clío: History and History teaching, 40, s/n. 
Rivière, A. (2020). La Historia de los conceptos para una ciudadanía crítica. Un proyecto de transferencia de la Begriffgeschichte al ámbito educativo. Con-Ciencia Social (segunda época), 3, 175-184. DOI:10.7203/con-cienciasocial.3.16796

Sáenz del Castillo, A. (2017). ¿Y Hitler que piensa sobre la guerra? Desarrollo y evaluación de una experiencia didáctica interactiva en el aprendizaje de la Segunda Guerra Mundial. Clio: History and History teaching, 43, 177-193.

Traverso, E. (2007). El pasado. Instrucciones de uso. Historia, memoria, política. Madrid: Marcial Pons.

Traverso, E. (2009). A sangre y fuego. De la guerra civil europea (1914-1945). Valencia: Universitat de València.

Traverso, E. (2017). La historia como campo de batalla. Interpretar las violencias del siglo XX. México: Fondo de Cultura Económica.

Traverso, E. (2018). Las nuevas caras de la derecha. Buenos Aires: Siglo XXI.

CÓMO CITAR ESTE ARTÍ́CULO

Hernández Sánchez, G. (2020). Didáctica de las violencias del siglo XX: Enzo Traverso y el concepto de Guerra civil europea. Didáctica de las ciencias experimentales y sociales, 39, 31-46. DOI: 10.7203/DCES.39.15665 